transported material, lying near the top of this considerable sequence of glacial deposits, then it seems reasonable to look on the whole series as a single " melt", only noteworthy in that the "raft" near the top is larger than usual (though larger ones are known elsewhere). If, on the other hand, they are in situ, then, as Lamplugh pointed out, there must have been a marine submergence of 100 feet or more, of which no sure record exists elsewhere in Eastern England-no record, at any rate, by shells or other marine organisms. Granting such a submergence, and that lack of confirmation only marks a deficiency in observation, even then the contacts suggest that the covering boulder-clay must be englacial dirt, quietly melted out from floating ice on to the sands below. The gravel may well have come from preliminary showers of such material, small enough to be washed clean. There are signs of disturbance and incorporation at the boulder-clay-gravel contact in an immediately adjacent pit (we see here a zone of gradual transition, about 1 foot thick), and that this should be so in one pit and not at all in the other, surely suggests a grounding berg or an irregular melt rather than the moving-in of a whole ice-sheet.

In any case, whether in situ or not (and I am inclined to think not), it looks as if the shelly clay of Kirmington is of late-glacial date, not interglacial. But I would like all interested to see the section as it is at present, for, in Lamplugh's concluding words, " any time spent upon the investigation of the Kirmington episode may produce results of wide consequence."

R. G. Carruthers.

NewCastre.

8th February, 1938.

\title{
THE ZONAL POSITION OF THE ELSWORTH ROCK.
}

Srr,-With regard to previous correspondence on this subject, will you allow me to point out that in my opinion Dr. Arkell is wrong in his interpretation of $A \mathrm{~mm}$. cordatus and therefore in his use of the term cordatum zone? Only chaos can result from Dr. Arkell's gratuitous alteration of previous revisors' work on this and other Corallian ammonites, for example, Amm. serratus. The reason given for wishing to alter the interpretation of the former species seems to me exactly the reason for not altering the latter. His plicatilis zone also is to me merely a meaningless assortment of heterochronous and incompletely known local developments. In the circumstances $I$ am afraid that the general reader will not greatly benefit by any discussion involving these zones; but it seems clear that Dr. Arkell does not realize how incompletely Upper Oxfordian time is represented by the Corallian deposits of England. Since Dr. Arkell himself again listed species (like the 
two Goliathiceras) from the Elsworth Rock which only occur (elsewhere) in the Upper Oxford Clay and the Lower Calcareous Grit, I am afraid that I cannot alter the views that I have already expressed.

Nor am I disposed to accept whole-heartedly Dr. Arkell's corrections of the identifications given in my Kachh Memoir, for example, of the Indian species which he does not know. But, since the personal element often influences identifications, it would weary your readers to pursue the subject. Suffice to say that only the latest elements of the Elsworth Rock ammonite fauna, i.e. those which date the bed are of transversarium age, and that in my opinion this greatly condensed rock also includes ammonites derived from older deposits.

What I objected to principally was that Dr. Arkell quoted from my text without reference to the table round which it was written, and which would have prevented any ambiguity about the various zonal names. Such terms as "transitional " or " confirmatory" lose their significance apart from the table, where the true position of Cardioceras rouillieri, for example, is clearly indicated.

The phrase about the Elsworth Rock at Üpware being in close association with a coral reef is a quotation and should have been printed as such. I was concerned with the ammonite succession and not with questions as to where the "rock" is supposed to be ; but I did establish the transversarium age of the coral reef the same as I did the Elsworth Rock. The "transition beds " with C. rouillieri, etc., are clearly not the Elsworth Rock but the beds transitional from Oxford Clay to the (now missing) Lower Corallian, which, at Elsworth, supplied some derived elements of the fauna. There is, then, in my view, no doubt that the Elsworth Rock is really a "mixed deposit".

British Musecm (Natural History),

L. F. Spath. $16 t h$ March, 1938.

\section{THE FLOOR OF THE ARABIAN SEA.}

Srk,-We have read with interest the recent criticism by Dr. G. M. Lees (GEol. Mag., 1938, p. 143) of a paper on the Floor of the Arabian Sea published by us, and we would like to take this opportunity of replying to the points raised in that letter.

First, it is incorrect to claim that we state on page 223 of the Geological Magazine for 1937 that on the Kuria Muria Islands a granite is intrusive into an overlying sandstone of Miocene Age. We do state that the granite is intrusive into a sandstone formation, but there is no mention on this page, or anywhere else in the paper, that the sandstone on the Kuria Muria Islands is of Miocene Age That the granite is intrusive was inferred by one of the authors (R. B. S. S.) both from the upward tilting of the practically horizontal strata on approaching the granite contact, and from its 